\title{
LOCOREGIONAL ANESTHESIA FOR DENTAL TREATMENT IN CARDIAC PATIENTS: A COMPARATIVE STUDY OF 2\% PLAIN LIDOCAINE AND 2\% LIDOCAINE WITH EPINEPHRINE $(1: 100,000)$
}

\author{
Alessandra Batistela Laragnoit,' Ricardo Simões Neves, ${ }^{\mathrm{I}}$ Itamara Lúcia Itagiba

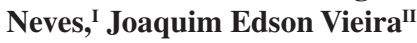

doi: $10.1590 / \mathbf{S 1 8 0 7 - 5 9 3 2 2 0 0 9 0 0 0 3 0 0 0 0 5}$

Laragnoit AB, Neves RS, Neves ILI, Vieira JE. Locoregional anesthesia for dental treatment in cardiac patients: a comparative study of $2 \%$ plain lidocaine and 2\% lidocaine with epinephrine (1:100,000). Clinics. 2009;64(3):177-82.

OBJECTIVES: This study analyzes hemodynamic changes in patients with cardiac valvular diseases submitted to dental treatment under local anesthesia containing epinephrine.

METHODS: This randomized clinical trial was performed at the Dental Division of the Instituto do Coração do Hospital das Clínicas da Faculdade de Medicina da Universidade de São Paulo (Brazil). Patients were separated into two groups with the help of an aleatory number table: $2 \%$ plain lidocaine $(\mathrm{PL}, \mathrm{n}=31)$ and $2 \%$ lidocaine with epinephrine $(1: 100,000)(\mathrm{LE}, \mathrm{n}=28)$. Blood pressure, heart rate, oxygenation and electrocardiogram data were all recorded throughout the procedure. State and trait anxiety levels were measured.

RESULTS: Fifty-nine patients were selected for the LE group ( $n=28$ ), with an average age of $40.3 \pm 10.9$, or for the PL group $(n=31)$, age $42.2 \pm 10.3$. No differences were shown in blood pressure, heart rate and pulse oximetry values before, during and after local anesthesia injection between the two groups. State and trait anxiety levels were not different. Arrhythmias observed before dental anesthesia did not change in shape or magnitude after treatment. Complaints of pain during the dental procedure were more frequent within the PL group, which received a higher amount of local anesthesia.

CONCLUSION: Lidocaine with epinephrine $(1: 100,000)$ provided effective local anesthesia. This treatment did not cause an increase in heart rate or blood pressure and did not cause any arrhythmic changes in patients with cardiac valvular diseases.

KEYWORDS: Anesthesia; Local; Lidocaine; Dental care; Arrhythmias; Cardiac; Anxiety.

\section{INTRODUCTION}

Pain and fear during dentistry procedures can be important factors that render the experience as an adverse event. In a study carried out by the Committee for the Prevention of Systemic Complications During Dental Treatment of the Japan Dental Society of Anesthesiology, it was observed that $60 \%$ of dental treatment complications

IDivision of Dental Care, Instituto do Coração, Faculdade de Medicina da Universidade de São Paulo - São Paulo/SP, Brazil.

"Division of Anesthesia, Hospital das Clínicas, Faculdade de Medicina da Universidade de São Paulo - São Paulo/SP, Brazil.

Tel. : 55113082.4076

Email : joaquimev@usp.br

Received for publication on August 06, 2008

Accepted for publication on November, 01, 2008 involved neurogenic shock that happened, in most of the cases, as a result of dental extractions and endodontic procedures during or after anesthesia. ${ }^{1}$ Researchers observed a significant increase from 5 to $12 \mathrm{mmHg}$ in the systolic blood pressure in patients submitted to root surface debridement without local anesthesia. ${ }^{2,3}$

Patients with heart valvular disease constitute a group in which local anesthesia should be effective, considering that pain is responsible for the liberation of endogenous catecholamines that can activate hemodynamic disturbances, including increases in blood pressure, heart rate and the frequency of arrhythmias. ${ }^{4-11}$

The epinephrine vasoconstrictor that is added to local anesthetics in dentistry treatment provides excellent anesthesia and bleeding control. ${ }^{5-7}$ Although its use in healthy 
patients has become a common practice, the use in patients with cardiac diseases is still controversial. No significant hemodynamic response to lidocaine dental anesthesia (with or without epinephrine) was found in healthy young patients, but some degree of adrenergic activation was detected during minor oral surgery in volunteers and in cardiac transplant recipients. ${ }^{8-10}$

The purpose of this study was to investigate the safety and efficiency of $2 \%$ lidocaine with epinephrine (1:100,000) when compared to plain lidocaine in patients with valvular disease. To this end, we observed hemodynamic parameters, analyzed the electrocardiogram data and quantified clinical symptoms.

\section{METHODS}

This randomized clinical trial was performed in the Dental Division of the Instituto do Coração do Hospital das Clínicas da Faculdade de Medicina da Universidade de São Paulo (Brazil) (Clinical Trials, registry number NCT00669838). The study was previously approved by the local ethics committee. Patients were fully informed of the purposes of the study and the procedures involved, and written consent was obtained. Patients with acquired valvular disease, aged between 18-65 years and in need of dental surgery (tooth extraction) or mandibular restorative dentistry participated in this study. Patients exhibited a variety of valvular diseases: mitral double lesion, aortic double lesion, mitral stenosis, aortic stenosis, mitral regurgitation, aortic regurgitation, atrial fibrillation, tricuspid regurgitation, cardiac functional classification and mitral valve prolapse. Patients who had platelets counts lower than 70.000 or INR $>3$ were excluded. ${ }^{12}$

Participants were directed to maintain their routine medication regimen. They were allocated into two groups: LE (2\% lidocaine with epinephrine [1:100,000]) and PL ( $2 \%$ lidocaine), according to a randomized table. Patients received prophylactic antibiotics following the American Heart Association guidelines.

The anesthetic was injected using the inferior alveolar nerve block technique with a slow infiltration $(>60$ seconds). When a molar surgery was necessary, a quarter of the anesthetic cartridge was injected distal to the last molar in the mandible, in order to achieve buccal nerve anesthesia.

All patients received one cartridge $(1.8 \mathrm{ml})$ of the anesthetic solution immediately at the beginning of the procedure; further injections were applied according to patients' symptoms or request. The cartridges were covered with a white strip to prevent patients and study administrators from reading any information pertaining to the anesthetic solution. These local anesthetics were prepared by a blinded professional.

Hemodynamic values including noninvasive blood pressure, heart rate, electrocardiograms of three derivations (D1, AVF and V1) and pulse oximetry were registered with a Dixtal DX2010 monitor (São Paulo- Brazil). The EKG data was recorded continually. All intervals were recorded to facilitate analysis of supraventricular and ventricular arrhythmic waves, as well as the ST segment. A cardiologist blinded to the procedure group analyzed the EKG data.

The patients were kept in a seated position at 45 degrees for 15 minutes before the dental procedure; their hemodynamic values at the 1 st and 15 th minutes were recorded. These parameters were considered as basal values for the patient. During the procedure, measurements were taken every 5 minutes and also at 1 and 15 minutes after the end of the procedure.

The Spielberger State-Trait Anxiety Inventory (STAI) was used to measure anxiety levels. The STAI was administered to all patients prior to dentistry procedures in order to record any measurable anxiety. ${ }^{13}$ An additional questionnaire containing information about pain, dizziness, palpitation, diaphoresis, anxiety, angina, fainting and syncope was administered at the end of the procedure, in order to evaluate the stress experienced during the treatment.

At the end of the procedure, the patients were instructed to take notes for additional comparison among the groups.

\section{Statistical analysis}

The presence of arrhythmia was considered as unknown before and as $90 \%$ after the procedure. The Yates correction factor was used for proportionate sample sizes, with the power of the test being $80 \%$ and alpha set to 0.05 , resulting in 25 patients for each group.

The electrocardiogram events registered during interventions were compared by the McNemar test, considering the presence or absence of previous arrhythmias. We also performed a Kruskal-Wallis test to evaluate the arrhythmias within the LE and PL groups and a MannWhitney test to compare the frequencies between the two groups. A Student's t-test was used to compare the blood pressure and heart rate before and after the procedure. ANOVA for repeated measures was used to compare blood pressure and heart rate within a group during the procedure. Pulse oximetry values and anesthetic volumes were compared by a Mann-Whitney test; duration of anesthesia was compared using the t-test. Fisher's exact test, as well as the STAI questionnaire, was used to determine the frequency of symptoms described by the patients during the procedure. Results were considered statistically significant at $\mathrm{p}<0.05$. 


\section{RESULTS}

Fifty-nine patients with valvular disease participated in this study. Their age (LE $40.3 \pm 10.9$ and PL $42.2 \pm 10.3$ years), weight (LE 63.97 \pm 19.32 and PL $59.44 \pm 15.85$ $\mathrm{kg}$ ) and height (LE $164 \pm 09$ and PL $161 \pm 09 \mathrm{~cm}$ ) did not differ, nor did the prevalence of valvular disease. The anesthesia duration for the LE group was longer $(\mathrm{P}=0.004)$ than that of the PL group (Table 1). Similarly, the number of local anesthesia cartridges used was higher in the PL group ( 3 cartridges for $75 \%$ of the cases, $\mathrm{P}=0.008$ ). Blood pressure before and after the dental procedures, or during the treatment period, did not show any significant difference (Table 2, Figure 1).

The comparison of heart frequency among the two groups before ( $\mathrm{P}=0.69)$ and after the procedure $(\mathrm{P}=0.87)$ indicated an absence of alterations in this variable for the volume of epinephrine used. The heart rhythm during the perioperative period also failed to exhibit alterations, with a P-value of 0.907 for the LE group and 1.000 for the PL group. The unaffected pulse oximetry values suggested that the patients did not have any breathing problems during the dental intervention.
Three statistical tests were used to analyze electrocardiographic alterations after the administration of local anesthesia. There was not any noticeable difference for any of the analyses performed among the groups, considering that the arrhythmias observed before the dental anesthesia did not change in form or amplitude after the anesthesia procedure. The McNemar test with the Yates correction for continuity showed no difference, considering five patients from the LE group with rhythmic heart rates that became arrhythmic $(\mathrm{p}=0.07)$ and three rhythmic heart rates among PL patients that became arrhythmic $(\mathrm{p}=0.5)$. The medians for irregular complexes among the PL and LE groups showed no difference when compared by a Mann-Whitney test. Finally, the medians for irregular complexes did not differ within a group when comparing the pre-, post- and intraoperative dental treatment values by Kruskal-Wallis one way analysis of variance (Table 3 ).

There was no difference in anxiety levels among the groups, either for state anxiety or trait anxiety (Table 1). Furthermore, the Fisher exact test results for symptoms showed no dissimilarities. However, when the pain was analyzed, the PL group presented more complaints as compared to the LE group ( $\mathrm{P}=0.03)$.

Table 1 - Demographic data, procedure and anesthetic length, STAI results and valvular disease distribution

\begin{tabular}{lcc}
\hline & PL $(\mathrm{n}=31)$ & LE $(\mathrm{n}=28)$ \\
\hline Age, years (mean \pm SD) & $42.1 \pm 10.3$ & $40.3 \pm 10.9$ \\
Weight, $\mathrm{kg}($ mean $\pm \mathrm{SD})$ & $59.4 \pm 15.8$ & $63.1 \pm 19.3$ \\
Height, cm (mean \pm SD) & $161 \pm 09$ & $164 \pm 09$ \\
Procedure length (median [25-75\%] & $33.0[27.5-41.0 \%]$ & $39.5[32.0-53.5 \%]$ \\
Anesthetic duration (mean \pm SD) & $111.6 \pm 74.4 *$ & $175.5 \pm 76.6$ \\
State-anxiety level (STAI) & $36.1 \pm 8.3$ & $36.9 \pm 9.1$ \\
Trait-anxiety level (STAI) & $44.4 \pm 11.6$ & $42.1 \pm 10.5$ \\
Mitral disease & 22 & 22 \\
Aortic disease & 10 & 10 \\
Tricuspid disease & 4 & 3 \\
\hline
\end{tabular}

$* \mathrm{p}<0.004$ (t-test)

Table 2 - Values (mean \pm SD) for systolic, diastolic and median blood pressure, before and after dental procedure in the PL and LE groups

\begin{tabular}{|c|c|c|c|c|}
\hline Variable & LE & PL & LE & PL \\
\hline Heart Pressure $(\mathrm{mmHg})$ & \multicolumn{2}{|c|}{ Before dental procedure } & \multicolumn{2}{|c|}{ After dental procedure } \\
\hline Systolic & $119.75 \pm 24.03$ & $124.61 \pm 19.32$ & $122.36 \pm 4.98$ & $127.16 \pm 3.99$ \\
\hline P-value & \multicolumn{2}{|c|}{0.39} & \multicolumn{2}{|c|}{0.45} \\
\hline Diastolic & $68.82 \pm 13.36$ & $71.77 \pm 14.48$ & $73.21 \pm 19.42$ & $75.71 \pm 16.68$ \\
\hline P-value & \multicolumn{2}{|c|}{0.42} & \multicolumn{2}{|c|}{0.59} \\
\hline Mean & $89.11 \pm 15.94$ & $93.87 \pm 14.21$ & $92.93 \pm 23.50$ & $9613 \pm 16.07$ \\
\hline P-value & \multicolumn{2}{|c|}{0.23} & \multicolumn{2}{|c|}{0.54} \\
\hline
\end{tabular}




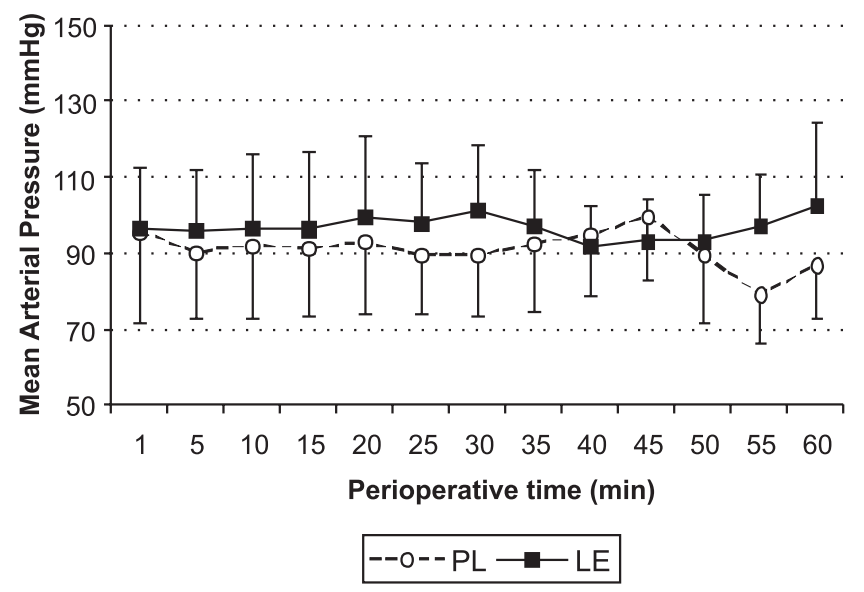

One-Way Repeated Measures Analysis of Variance: PL, $\mathrm{p}=0.85$; LE, $\mathrm{p}=0.67$.

Figure 1 - Mean arterial pressure for PL (mean - SD) and LE groups (mean $+\mathrm{SD})$ throughout the procedure

\section{DISCUSSION}

Local anesthetic consisting of $2 \%$ lidocaine and epinephrine [1:100,000] did not alter the previously registered arrhythmic conditions and did not change the heart rate or blood pressure among patients with cardiac valvular disease, suggesting its safety for use in minor dentistry interventions.

Epinephrine is one of the most commonly used vasoconstrictors in association with local anesthesia in dentistry; it is indisputably the most studied. ${ }^{6,714,15}$ Its use in dentistry, as well as that of other vasoconstrictors, is widely accepted. There are few studies in the literature that show its use in patients with valvular diseases, since most of those studies are performed in patients with hypertension and coronary artery disease.15,16 On the other hand, valvular diseases are involved in at least $18 \%$ of the ambulatory movements of a cardiology hospital and about
$30 \%$ of cardiac surgeries. ${ }^{17}$ Such patients invariably require additional unexpected procedures.

Adequate pain control is essential during dental procedures. The oral cavity is densely filled with paintriggering structures. Substances that provide more profound anesthesia are necessary to prevent stress. In addition, an increase in the heart rate by about 12 beats per minute can be caused by simply sitting down in the dental chair. A simple and brief talk with the dentist concerning the dental problem increases systolic blood pressure by approximately 5 or $6 \mathrm{mmHg} .{ }^{4}$

In this study, the administration of local anesthesia without a vasoconstrictor drove more patients to complain of pain during dental surgery. Lidocaine alone exhibited unsatisfactory pain control; when combined with epinephrine, this same anesthetic provided a more intense blocking of large- and small-diameter nerve fibers. ${ }^{7,18,19}$

Despite the absence of additional arrythmias or variations in heart rate or blood pressure, the PL group exhibited a higher cardiac rate and blood pressure than the LE group. This suggests that a fast-acting local anesthetic results in greater patient susceptibility to stress, requiring more careful attention from the dentist during dental treatment.

The findings of this study are in agreement with the results of other investigations in which patients with cardiac problems received $2 \%$ lidocaine with epinephrine (1:100,000) during dental treatment and hemodynamic parameters did not change significantly. ${ }^{7,15,20-24}$ We observed no increase in any symptoms in the LE group, in accordance with a previous study in which the patients did not show any symptoms during treatment with a local anesthetic that contained a vasoconstrictor. ${ }^{15}$

Epinephrine is an arrhythmogenic substance. However, there is no consensus regarding the amount of this catecholamine to be used in dentistry in order to maintain a margin of safety with cardiac patients. The present study

Table 3 - Number of irregular complexes during dental treatment periods in the PL and LE groups (median [25\%-75\%])

\begin{tabular}{|c|c|c|c|}
\hline Arrhythmias & $\mathrm{LE}(\mathrm{n}=28)$ & $\operatorname{PL}(\mathrm{n}=31)$ & Mann-Whitney (p) \\
\hline \multicolumn{4}{|c|}{ Supraventricular } \\
\hline Pre-operative & $1.00[1.00-1.10]$ & $1.00[1.00-1.10]$ & 0.57 \\
\hline Intraoperative & $1.00[1.00-1.22]$ & $1.00[1.00-1.10]$ & 0.96 \\
\hline Post-operative & $1.00[1.00-1.10]$ & $1.00[1.00-1.02]$ & 0.56 \\
\hline Kruskal-Wallis (p) & 0.91 & 0.42 & \\
\hline \multicolumn{4}{|c|}{ Ventricular } \\
\hline Pre-operative & $1.00[1.00-1.10]$ & $1.00[1.00-1.10]$ & 0.67 \\
\hline Intraoperative & $1.00[1.00-1.00]$ & $1.00[1.00-1.35]$ & 0.10 \\
\hline Post-operative & $1.00[1.00-1.00]$ & $1.05[1.00-1.10]$ & 0.09 \\
\hline Kruskal-Wallis (p) & 0.33 & 0.39 & \\
\hline
\end{tabular}


evaluated the continuous recordings of electrocardiograms before, during and after the dental procedure. The arrhythmias observed were analyzed according to frequency, form and amplitude, as well as depression of the ST segment. Cardiac patients exhibit frequent arrhythmias due to their established cardiac condition; the injection of a local anesthetic containing epinephrine did not alter these existing conditions. These findings are in accordance with other studies in which ST depression was not observed during dental treatment of cardiac patients when utilizing a local anesthetic that contained a vasopressor. 11 Blinder et al. analyzed the ST depression, cardiac rhythm and the number of premature heart beats in cardiac patients submitted to dental extractions under a local anesthetic containing a vasopressor. When the local anesthetic contained a vasopressor, there was a high incidence of tachycardia but less arrhythmia or ST depression, as compared with a previous study that used anesthetic alone. ${ }^{16,25}$

The present data indicate that the use of $2 \%$ lidocaine with epinephrine $(1: 100,000)$ in patients with valvular disease represents a safe and effective anesthetic procedure. There were no additional significant alterations in the electrocardiogram data and no increase in blood pressure with this treatment. This group of cardiac patients experienced a more profound anesthesia and apparently remained more comfortable and free of pain.

\section{REFERENCES}

1. Matsuura H. Analysis of systemic complications and deaths during dental treatment in Japan. Anesth Prog. 1989;36:223-5.

2. Grant DA, Lie T, Clark SM, Adams DF. Pain and discomfort levels in patients during root surface debridement with sonic metal or plastic inserts. J Periodontol. 1993, 64:645-50.

3. Brand HS, Gortzak RA, Palmer-Bouva CC, Abraham RE, AbrahamInpjin L. Cardiovascular and neuroendocrine responses during acute stress induced by different types of dental treatment. Int Dent J. 1995;45:45-8.

4. Brand HS, Abraham-Inpijn L. Cardiovascular responses induced by dental treatment. Eur J Oral Sci. 1996;104:245-52.

5. Cioffi GA, Chernow B, Glahn RP, Terezhalmy GT, Lake CR. The hemodynamic and plasma catecholamine responses to routine restorative dental care. J Am Dent Assoc. 1985;11:67-70.

6. Jastak JT, Yagiela JA. Vasoconstrictors and local anesthesia: a review and rationale for use. J Am Dent Assoc. 1983;107:623-30.

7. Davenport RE, Porcelli RJ, Iacono VJ, Bonura CF, Mallis GI, Baer PN. Effects of anesthetics containing epinephrine on catecholamine levels during periodontal surgery. J Periodontol. 1990;61:553-8.

8. Chernow B, Balestrieri F, Ferguson CD, Terezhalmy GT, Fletcher JR, Lake CR. Local dental anesthesia with epinephrine. Minimal effects on the sympathetic nervous system or on hemodynamic variables. Arch Intern Med. 1983;143:2141-3.

9. Salonen M, Forssell H, Scheinin M. Local dental anaesthesia with lidocaine and adrenaline. Effects of plasma catecholamines, heart rate and blood pressure. Int J Oral Maxillofac Surg. 1988;17:392-4.

10. Meechan JG, Perry G, Rattray DT, Thomason JM. Effects of dental local anaesthetics in cardiac transplant recipients. Br Dent J. 2002;192:1613.

11. Vanderheyden PJ, Williams RA, Sims TN. Assessment of ST segment depression in patients with cardiac disease after local anesthesia. J Am Dent Assoc. 1989;119: 407-12.
12. Brandão CMA, Pomerantzeff PMA, Souza LR, Tarasoutchi F, Grimberg M, Oliveira SA. Risk factors to hospital mortality valvar reoperations. Rev Bras Cir Cardiovasc. 2002;17:345-51.

13. Gorenstein C, Andrade L. Validation of a Portuguese Version of the Beck Depression Inventory and the State-Trait Anxiety Inventory in Brazilian subjects. Brazilian J Med Biol Research. 1996;29:453-57.

14. Tolas AG, Pflug AE, Halter JB. Arterial plasma epinephrine concentrations and hemodynamic responses after dental injection of local anesthetic with epinephrine. J Am Dent Assoc. 1982,104:41-3.

15. Niwa H, Sugimura M, Satoh Y, Tanimoto A. Cardiovascular response to epinephrine-containing local anesthesia in patients with cardiovascular disease. Oral Surg Oral Med Oral Pathol Oral Radiol Endod. 2001,92: 610-6.

16. Blinder D, Manor Y, Shemesh J, Taicher S. Electrocardiographic changes in cardiac patients having dental extractions under a local anesthetic containing a vasopressor. J Oral Maxillofac Surg. 1998;56:1399-402.

17. Grinberg M. Valvopatias Adquiridas: uma visão geral. In: Porto CC, editor. Doenças do Coração. Rio de Janeiro: Guanabara Koogan;1998. p.703-708.

18. Kabambe WM, Rood JP, Sowray JH. A comparison of plain 2 per cent lignocaine and 2 per cent lignocaine with adrenaline in local analgesia for minor oral surgery. J Dent. 1982;10:136-9.

19. Sakura S, Sumi M, Morimoto N, Saito Y. The addition of epinephrine increases intensity of sensory block during epidural anesthesia with lidocaine. Reg Anesth Pain Med. 1999;24:541-6.

20. Meechan JG, Thomson CW, Blair GS, Rawlins MD. The biochemical and haemodynamic effects of adrenaline in lignocaine local anaesthetic solutions in patients having third molar surgery under general anaesthesia. Br J Oral Maxillofac Surg 1991;29:263-8.

21. Fernieini EM, Bennett JD, Silverman DG, Halaszynski TM Hemodynamic assessment of local anesthetic administration by laser Doppler flowmetry. Oral Surg Oral Med Oral Pathol Oral Radiol Endod. 2001;91:526-30. 
22. Neves RS, Neves IL, Giorgi DM, Grupi CJ, Cesar LA, Hueb W, et al Effects of epinephrine in local dental anesthesia in patients with coronary artery disease. Arq Bras Cardiol. 2007;88(5):545-51.

23. Conrado VC, de Andrade J, de Angelis GA, de Andrade AC, Timerman L, Andrade MM, et al. Cardiovascular effects of local anesthesia with vasoconstrictor during dental extraction in coronary patients. Arq Bras Cardiol. 2007;88(5):507-13.
24. Elad S, Admon D, Kedmi M, Naveh E, Benzki E, Ayalon S, et al. The cardiovascular effect of local anesthesia with articaine plus 1:200,000 adrenalin versus lidocaine plus 1:100,000 adrenalin in medically compromised cardiac patients: a prospective, randomized, double blinded study. Oral Surg Oral Med Oral Pathol Oral Radiol Endod. 2008;105(6):725-30.

25. Bernards CM, Kopacz DJ. Effect of epinephrine on lidocaine clearance in vivo: a microdialysis study in humans. Anesthesiology. 1999;91:9628 . 